\title{
Structural organization of DNA-protein complexes of chromatin studied by vibrational and electronic circular dichroism
}

\author{
Alexander Polyanichko ${ }^{\mathrm{a}, *}$ and Helmut Wieser ${ }^{\mathrm{b}}$ \\ ${ }^{a}$ Department of Molecular Biophysics, Faculty of Physics of Saint-Petersburg State University and \\ Institute of Cytology RAS, Saint-Petersburg, Russia \\ ${ }^{\mathrm{b}}$ Department of Chemistry, University of Calgary, Calgary, Alberta, Canada
}

\begin{abstract}
Structure and functioning of chromatin is determined by interactions of DNA with numerous nuclear proteins. The most abundant and yet not completely understood non-histone chromosomal proteins are those belonging to a High Mobility Group (HMG) namely HMGB1. The interplay of this protein on DNA with linker histone $\mathrm{H} 1$ and other proteins determines both structure and functioning of the chromatin. A combination of UV and IR absorption and circular dichroism (CD) spectroscopy was applied to investigate the structure and formation of large supramolecular DNA-protein complexes. This combination of techniques was used to overcome limitations of UV-CD (ECD) spectroscopy due to considerable light scattering in such solutions. Based on the analysis of FTIR and UV circular dichroism spectra and AFM imaging the interaction of DNA with high-mobility group non-histone chromatin protein HMGB1 and linker histone H1 was studied.
\end{abstract}

Keywords: DNA, chromatin, HMGB1, circular dichroism, VCD

\section{Introduction}

Structural organization of DNA in chromatin has been extensively studied for many years. When the structure of nucleosome was solved, the investigations of the higher levels of the structural organization became one of the most important steps in understanding the chromatin functioning $[17,18]$. A great variety of DNA-binding proteins interact with DNA forming intricate DNA-protein complexes. DNA-bound protein factors normally cooperate to assemble higher-order nucleoprotein structures in which multiple protein-DNA and protein-protein contacts increase the specificity and stability of the final complexes [4]. There is the whole class of 'architectural' proteins in chromatin that perform these structural functions. Among such proteins are HMGB-domain proteins. Their common features are the DNA-binding domains, often called HMG-Box domains [11,13] whose structure is highly conservative. Some of the proteins in this family contain only one HMGB-domain but a great number of others possess two or more of these domains. The members of the family are able to distinguish and preferably bind to DNA four-way junctions, binding sites of the anticancer drug cisplatin and different bends

\footnotetext{
* Corresponding author: Dr. Alexander Polyanichko, Associate Professor at the Department of Molecular Biophysics, Faculty of Physics of Saint-Petersburg State University, 1 Uljanovskaya Str., Stary Petergoff, Saint-Petersburg 198504, Russia. Tel.: +7 812428 4388; Fax: +7 812428 7240; E-mail: polyanichko@gmail.com.
} 
and crossovers in general [14]. Our previous studies revealed the ability of HMGB1 protein to induce formation of ordered multi-molecular complexes upon binding to DNA [2,9]. However, their structural investigation using UV-CD, the spectroscopic technique that can be routinely applied to DNA and protein studies, is limited due to the emerging light scattering in the solutions resulting from the big size of the complexes. The aim of the present study is to demonstrate the possibility to study such DNA-protein complexes spectroscopically combining UV-CD with IR circular dichroism.

\section{Materials and methods}

To obtain the DNA-protein complexes, histone H1 (MW = 21,000) and non-histone protein HMGB1 (MW $=26,500)$ were used. Both proteins were isolated from calf thymus as described earlier [2]. Calf thymus DNA (Sigma) was sonicated as described elsewhere [6]. All aqueous solutions were prepared using double-distilled water. Heavy water $\left(99.9 \% \mathrm{D}_{2} \mathrm{O}\right)$ for the IR experiments was purchased from Sigma. The protein content in the system was described in terms of the protein to DNA weight to weight ratio $(r, \mathrm{w} / \mathrm{w})$. In all complexes the $\mathrm{H} 1$ to HMGB1 w/w ratio was maintained at $1: 1$. UV absorbance and ECD spectra of the complexes were recorded with a Jasco-715 spectropolarimeter (Jasco Corp., Japan) in $1 \mathrm{~mm}$ cylindrical quartz cells; concentration of DNA in the samples was $0.3 \mathrm{mg} / \mathrm{ml}$. All VCD and IR spectra were measured simultaneously in the range of $1800-750 \mathrm{~cm}^{-1}$ in $\mathrm{D}_{2} \mathrm{O}$ with the VCD instrument described earlier [15]. Concentration of DNA in the samples for VCD-measurements was $35 \mathrm{mg} / \mathrm{ml}$. The detailed description of both UV and IR spectroscopic approaches is given elsewhere [6]. The AFM images were obtained on mica in a tapping mode with NanoWizard microscope (JPK Instruments, Germany).

\section{Results and discussion}

One of the most useful tools for investigating the structure of biological macro-molecules is ultraviolet circular dichroism (CD). However, the applicability of the method appeared to be limited for the investigation of DNA-protein assemblies. In most cases, large DNA-polymer complexes cause considerable light scattering, which affects the shape of the spectral bands resulting in " $\psi$-type" CD spectra. In such a situation, direct structural analysis of the $\mathrm{CD}$ data is impossible. To overcome this limitation we combine UV-CD with another structure-sensitive spectroscopic approach: infrared or vibrational, CD (VCD). Being a chiroptical technique, like its counterpart in the UV region, VCD is also very sensitive to structural changes in the macromolecules, but in addition is considerably more informative for structural analysis compared to ECD. For example, unlike ECD, VCD spectra reveal not only DNA conformations, i.e., A, $\mathrm{B}$ or $\mathrm{Z}$ form, but also the mutual orientation of the different chemical groups within the DNA as well as their participation in interactions with other molecules or ions.

To demonstrate the applicability of this approach for investigating supramolecular DNA-protein systems, we prepared complexes between DNA and two chromosomal proteins: histone $\mathrm{H} 1$ and non-histone protein HMGB1, which are some of the most abundant chromatin proteins. Both proteins play an important role in the structural organization of chromatin at the post nucleosomal level. Both proteins also initiate the formation of supramolecular structures when complexed with DNA and each is able to induce $\psi$-type CD spectra. Acting together, they form supramolecular complexes at even smaller protein to DNA ratios. 


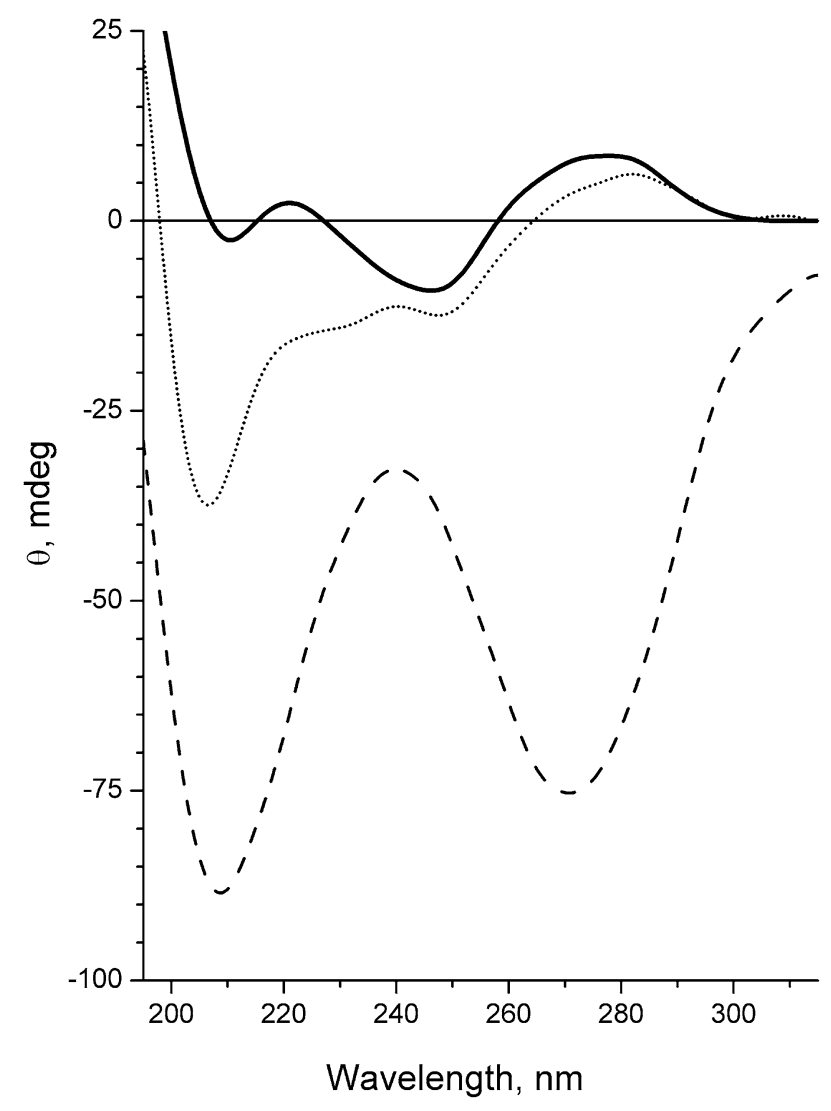

Fig. 1. CD spectra of DNA (solid line) and its complexes with non-histone protein HMGB1 and histone H1 at different protein to DNA ratios $(r, \mathrm{w} / \mathrm{w}): r=0.10$ (dotted line) and $r=0.25$ (dashed line). Concentration of DNA in all samples was $0.3 \mathrm{mg} / \mathrm{ml}$, optical path length was $1.0 \mathrm{~mm}$. The molar ratio of HMGB1 to H1 in the samples was maintained 1:1.

The typical UV-CD spectra of DNA and its complexes with proteins HMGB1 and H1 are given in Fig. 1. At low protein to DNA ratios the spectra of the complexes do not reveal any detectable changes in the secondary structure of the proteins, while decrease of DNA band in vicinity of $275 \mathrm{~nm}$ reveals DNA-protein interactions in the major groove of the DNA double helix. Considerable light scattering of the samples with $r=0.25$ leads to the formation of the $\psi$-type CD spectra. Such CD spectra indicate that large multi-molecular complexes are likely present in the solution. However, these spectra contain no information about the secondary structure of the macromolecules within the complexes. Nevertheless, IR/VCD spectra of the complexes with the same $(r=0.25)$ and even higher $(r=0.75)$ protein to DNA ratios, taken at higher DNA concentrations, essential for reliable VCD signal, give well-resolved spectral pattern (Fig. 2). Based on the previously published results $[1,3,5,6,10,12,16]$ it is possible to assign the major spectral features as summarized in the Table 1. Thus, IR/VCD spectra of large supramolecular complexes can be analyzed at higher protein to DNA ratios, unreachable for conventional UV-CD spectroscopy.

In both phosphate (1150-900 $\left.\mathrm{cm}^{-1}\right)$ and carbonyl $\left(1750-1500 \mathrm{~cm}^{-1}\right)$ regions interaction of DNA with the proteins at moderate $r$ values leads to decreasing intensity in IR absorbance, while at higher ratios intensity of the corresponding bands increases (Fig. 2). As it was shown earlier [6,8] this type of behav- 



Fig. 2. IR absorbance (left panel) and VCD (right panel) spectra of DNA (solid line) and its complexes with non-histone protein HMGB1 and histone $\mathrm{H} 1$ at different protein to DNA ratios $(r, \mathrm{w} / \mathrm{w}): r=0.25$ (dotted line) and $r=0.75$ (dashed line). The estimated level of noise for VCD signal of DNA at a particular wavenumber is given as separate trace (crosses). Concentration of DNA in all samples was $35 \mathrm{mg} / \mathrm{ml}$, optical path length was $0.050 \mathrm{~mm}$. The molar ratio of HMGB1 to H1 in the samples was maintained 1:1.

Table 1

The assignment of the major vibrations in the DNA-protein complex

\begin{tabular}{|c|c|c|}
\hline \multicolumn{2}{|c|}{ Band position, $\mathrm{cm}^{-1}$} & \multirow[t]{2}{*}{ Proposed assignment } \\
\hline Absorption & VCD & \\
\hline 1693 & $1698(-) / 1688(+)$ & Stretching vibrations of $\mathrm{C}_{2}=\mathrm{O}$ in thymine \\
\hline 1678 & $1662(+)$ & Stretching vibrations of $\mathrm{C}=\mathrm{O}$ groups in guanine and cytosine in presence of proteins \\
\hline 1644 & - & $\begin{array}{l}\mathrm{C}_{2}=\mathrm{O} \text { stretching of cytosine and } \mathrm{C}_{4}=\mathrm{O} \text { of thymine, } \mathrm{C}_{6}=\mathrm{O} \text { of guanine, } \\
\mathrm{C}=\mathrm{C} \text { of cytosine }\end{array}$ \\
\hline 1623 & $1638(+)$ & Adenine, thymine ring vibrations \\
\hline $\begin{array}{l}1572 \\
1560\end{array}$ & - & $\begin{array}{l}\text { Superposition of purine ring vibrations, including } C-\mathrm{ND}_{2}\left(1572 \mathrm{~cm}^{-1}\right) \text { and } \\
\mathrm{C}=\mathrm{N}\left(1560 \mathrm{~cm}^{-1}\right)\end{array}$ \\
\hline 1086 & $1091(-) / 1074(+)$ & Symmetrical vibrations of $\mathrm{O}=\mathrm{P}=\mathrm{O}$ bonds \\
\hline 1053 & $1056(+)$ & Stretching vibrations of $\mathrm{C}-\mathrm{O}$ bonds in sugar ring \\
\hline 1021 & $1034(-) / 1008(+)$ & Deoxyribose vibration \\
\hline 970 & $972(-)$ & Sugar ring vibrations \\
\hline $938,895,836$ & $936(-) / 896(+)$ & Sugar ring vibrations. DNA B-form markers \\
\hline
\end{tabular}

ior can be attributed to the initial stabilization of the double helix followed by numerous intermolecular interactions. Comparison of the spectra in the both regions at the different $r$ values reveals significant differences indicating that interactions of the proteins take place with the phosphate backbone and with the DNA bases, which is slightly different from the cases of DNA-HMGB1 and DNA-H1 complexes [7,8]. Changes in the spectra of the DNA bases at $1693 \mathrm{~cm}^{-1}$ (thymine $\mathrm{C}_{2}=\mathrm{O}_{2}$ ) and $1643 \mathrm{~cm}^{-1}$ (cytosine $\mathrm{C}=\mathrm{O}$ ) show dominant interactions between DNA and HMGB1, which occur in the minor groove. Weaker interactions of the histone $\mathrm{H} 1$ in the major groove can also be detected as slight changes in intensities at $1678 \mathrm{~cm}^{-1}$ (guanine $\mathrm{C}=\mathrm{O}$ ) as well as those at 1590, 1572 and $1560 \mathrm{~cm}^{-1}$ (guanine $\mathrm{C}=\mathrm{N}$ 


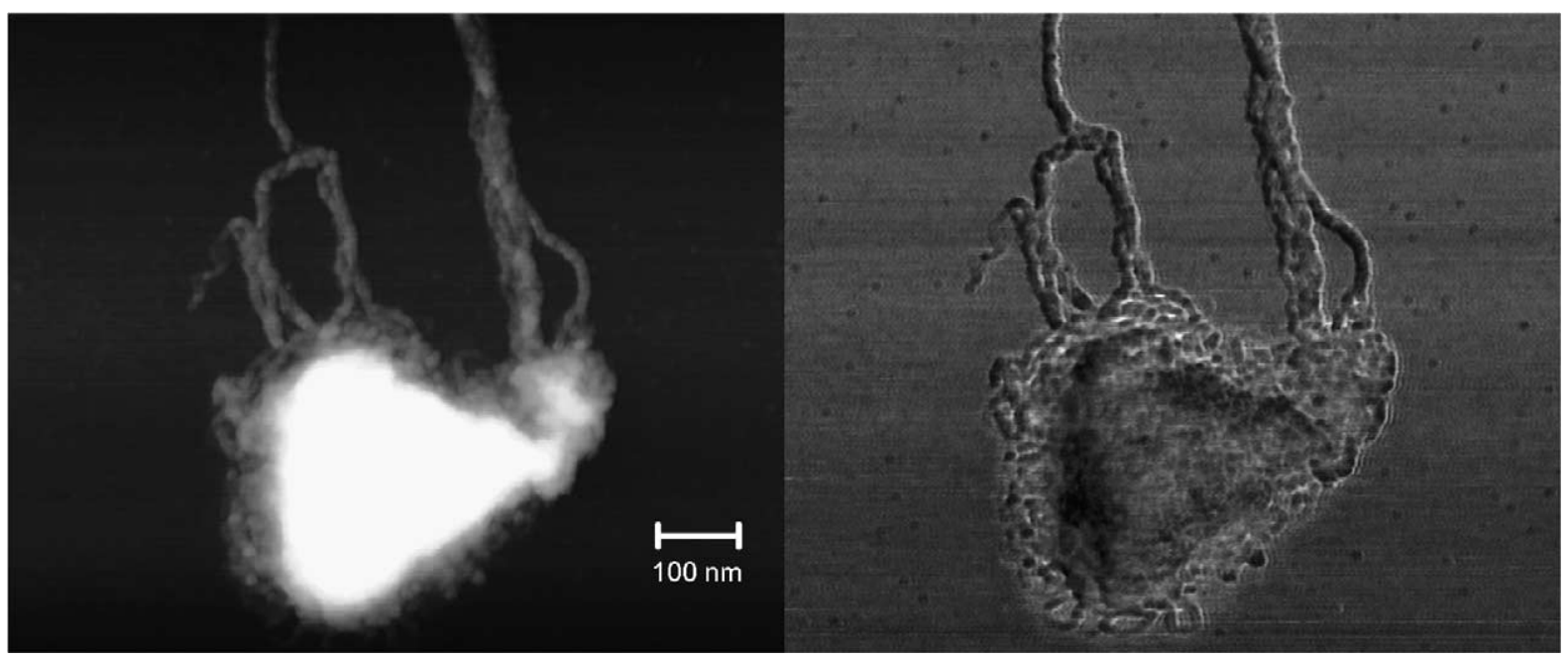

Fig. 3. AFM height trace (left panel) and phase trace (right panel) images of DNA-HMGB1-H1 complexes taken in a tapping mode on mica. Protein to DNA ratio $(r, \mathrm{w} / \mathrm{w}) r=1, \mathrm{HMGB} 1: \mathrm{H} 1$ molar ratio is 1:1. The scanned area is approximately $1 \mu \mathrm{m} \times 1 \mu \mathrm{m}$.

and $\mathrm{C}-\mathrm{ND}_{2}$ ). Protein binding is also accompanied by considerable DNA unwinding and bending, resulting in distortions in the mutual orientation of the bases, and thereby causes changes in corresponding VCD spectra at $\sim 1700 \mathrm{~cm}^{-1}, 1666(+) \mathrm{cm}^{-1}$ and $1636(+) / 1620(-) \mathrm{cm}^{-1}$. Decreasing coupling of phosphate groups at $1088(-) / 1068(+) \mathrm{cm}^{-1}$ and increasing VCD of the sugars at 1034 and $972 \mathrm{~cm}^{-1}$ indicate intensive binding of the histone $\mathrm{H} 1$ with phosphate groups and changes in geometry of the sugar-phosphate backbone.

Hence, we may conclude that acting together histone $\mathrm{H} 1$ and the non-histone chromatin protein HMGB1 do not demonstrate a competitive protein binding. Although binding of HMGB1 likely prevents binding of the histone molecules to the same site, partial neutralization of the negative charges of the phosphate groups of DNA by the histone facilitates HMGB1-DNA interactions and the formation of supramolecular complexes. To find out more about these large structures we applied atomic force microscopy, which shows (Fig. 3) that DNA molecules form some ordered fibrillar structures. This process is facilitated by the proteins, which hold together DNA molecules. The individual fibrils in turn interact with each other producing large shapeless aggregates, which easily precipitate in solutions.

Thus, the combination of UV and IR CD techniques allowed us to study large multi-molecular DNAprotein complexes, overcoming limitations due to the light scattering of the solutions.

\section{Acknowledgements}

The work was supported by RFBR (No. 09-08-01119), Government of Saint-Petersburg (A. Polyanichko) and NSERC (H. Wieser). The authors express their special gratitude to the Department of Chemistry at the University of Calgary for providing the instrumentation for UV and ECD spectroscopy; to the Microscopy and Imaging Facility at the University of Calgary for providing instrumentation for AFM imaging. We are also grateful to Dr. Elena Chikhirzhina (Institute of Cytology, RAS) for her help in protein purification. 


\section{References}

[1] V.V. Andrushchenko, H. Wieser and P. Bour, B-Z conformational transitions of nucleic acids monitored by vibrational circular dichroism. Ab initio interpretation of the experiment, J. Phys. Chem. B 106 (2002), 12623-12634.

[2] E.V. Chikhirzhina, A.M. Polyanichko, A.N. Skvortsov, E.I. Kostyleva, C. Houssier and V.I. Vorob'ev, HMG1 domains: the victims of circumstance, Mol. Biol. 36 (2002), 525-531.

[3] H. Fritzsche and C. Zimmer, Infrared studies of deoxyribonucleic acids, their constituents and analogues. 4. The binding sites of copper(II) in DNA, Eur. J. Biochem. 5 (1968), 42-44.

[4] R. Grosschedl, Higher-order nucleoprotein complexes in transcription: analogies with site-specific recombination, Curr. Opin. Cell Biol. 7 (1995), 362-370.

[5] T.A. Keiderling, Vibrational circular dichroism of proteins polysaccharides and nucleic acids, in: Physical Chemistry of Food Processes, Vol. 2, I.C. Baianu, H. Pessen and T. Kumosinski, eds, Van Norstrand-Reinhold, New York, 1993, pp. 307-337.

[6] A.M. Polyanichko, V.V. Andrushchenko, E.V. Chikhirzhina, V.I. Vorob'ev and H. Wieser, The effect of manganese(II) on DNA structure: electronic and vibrational circular dichroism studies, Nucleic Acids Res. 32 (2004), 989-996.

[7] A.M. Polyanichko, E.V. Chikhirzhina, V.V. Andrushchenko, E.I. Kostyleva, H. Wieser and V.I. Vorob'ev, The effect of $\mathrm{Ca}^{2+}$ ions on DNA compaction in the complex with non-histone chromosomal protein HMGB1, Mol. Biol. 38 (2004), 701-712.

[8] A.M. Polyanichko, E.V. Chikhirzhina, V.V. Andrushchenko, V.I. Vorob'ev and H. Wieser, The effect of manganese(II) on the structure of DNA/HMGB1/H1 complexes: electronic and vibrational circular dichroism studies, Biopolymers $\mathbf{8 3}$ (2006), 182-192.

[9] A.M. Polyanichko, E.V. Chikhirzhina, A.N. Skvortsov, E.I. Kostyleva, P. Colson, C. Houssier and V.I. Vorob'ev, The HMG1 ta(i)le, J. Biomol. Struct. Dyn. 19 (2002), 1053-1062.

[10] A.M. Polyanichko and H. Wieser, Vibrational circular dichroism and its applications to protein studies, in: Methods in Protein Structure and Stability Analysis: Vibrational Spectroscopy, E. Permyakov and V. Uversky, eds, Nova Science Publishers, New York, USA, 2007, pp. 267-302.

[11] C.M. Read, P.D. Cary, C. Crane-Robinson, P.C. Driscoll and D.G. Norman, Solution structure of a DNA-binding domain from HMG1, Nucleic Acids Res. 21 (1993), 3427-3436.

[12] H.A. Tajmir-Riahi, M. Naoui and R. Ahmad, The effects of $\mathrm{Cu}^{2+}$ and $\mathrm{Pb}^{2+}$ on the solution structure of calf thymus DNA: DNA condensation and denaturation studied by Fourier transform IR difference spectroscopy, Biopolymers 33 (1993), 1819-1827.

[13] J.O. Thomas and A.A. Travers, HMG1 and 2, and related 'architectural' DNA-binding proteins, Trends Biochem. Sci. 26 (2001), 167-174.

[14] A. Travers, Recognition of distorted DNA structures by HMG domains, Curr. Opin. Struct. Biol. 10 (2000), $102-109$.

[15] D. Tsankov, T. Eggimann and H. Wieser, Alternative design for improved FT-IR/VCD capabilities, Appl. Spectrosc. Rev. 49 (1995), 132-138.

[16] M. Tsuboi, Application of infrared spectroscopy to structure studies of nucleic acids, Appl. Spectrosc. Rev. 3 (1969), 45-90.

[17] A.P. Wolffe, Chromatin: Structure and Function, Academic Press, New York, 1998.

[18] J. Zlatanova and S.H. Leuba, Chromatin fibers, one-at-a-time, J. Mol. Biol. 331 (2003), 1-19. 


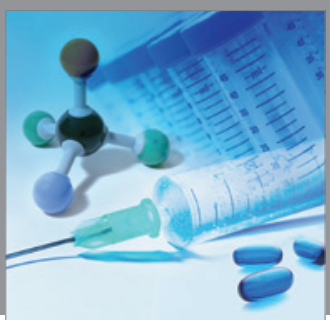

International Journal of

Medicinal Chemistry

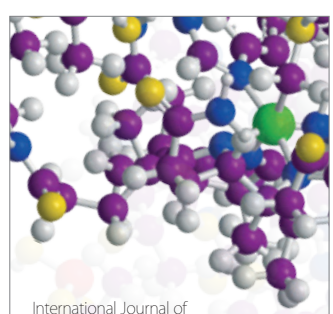

Carbohydrate Chemistry

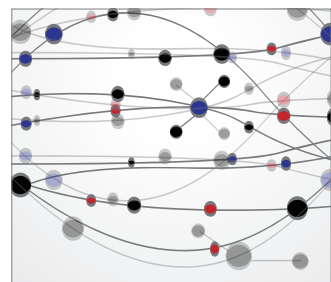

The Scientific World Journal
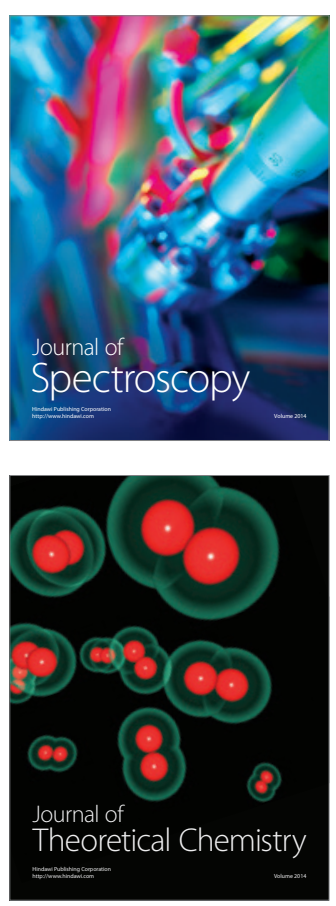
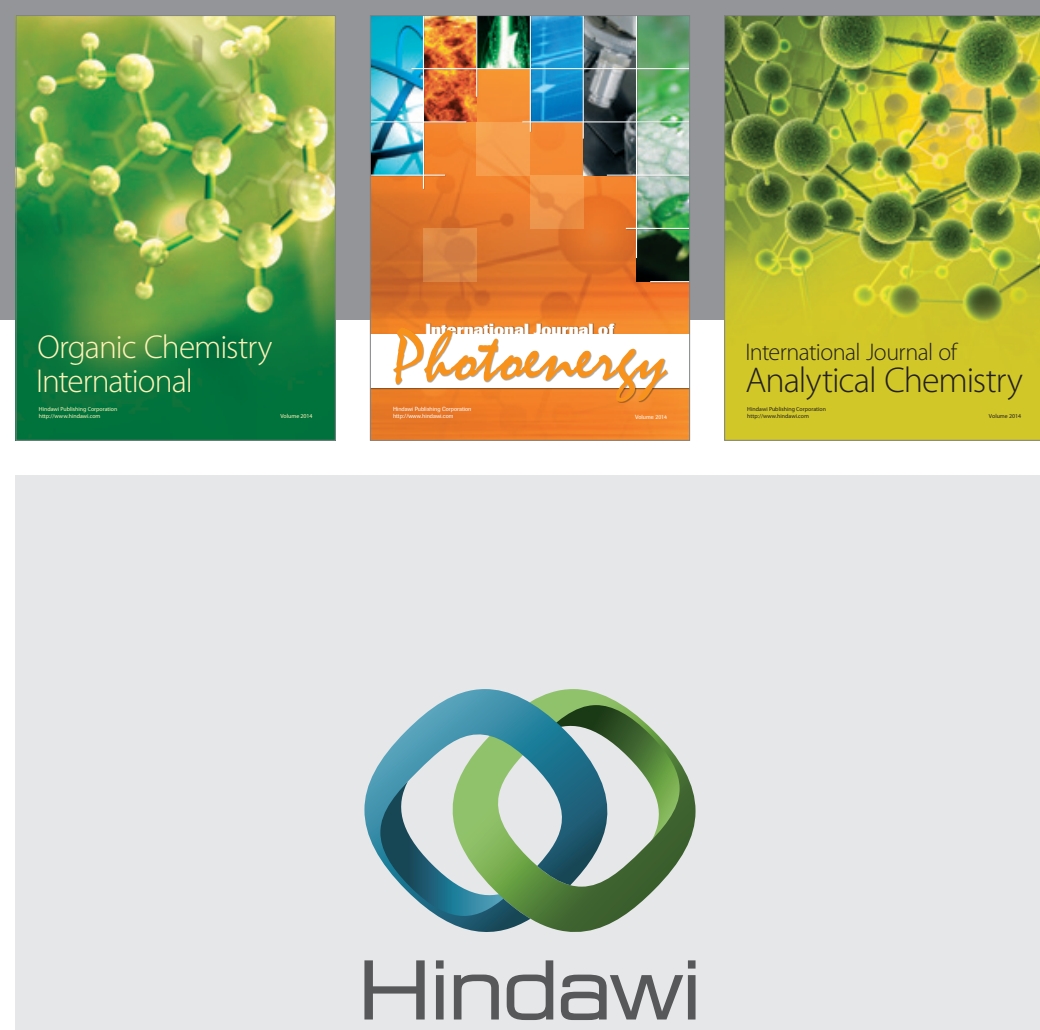

Submit your manuscripts at

http://www.hindawi.com
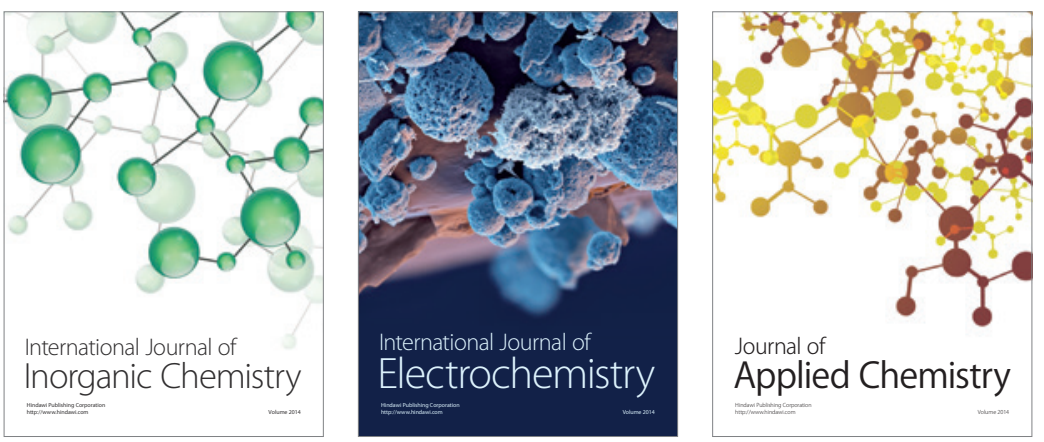

Journal of

Applied Chemistry
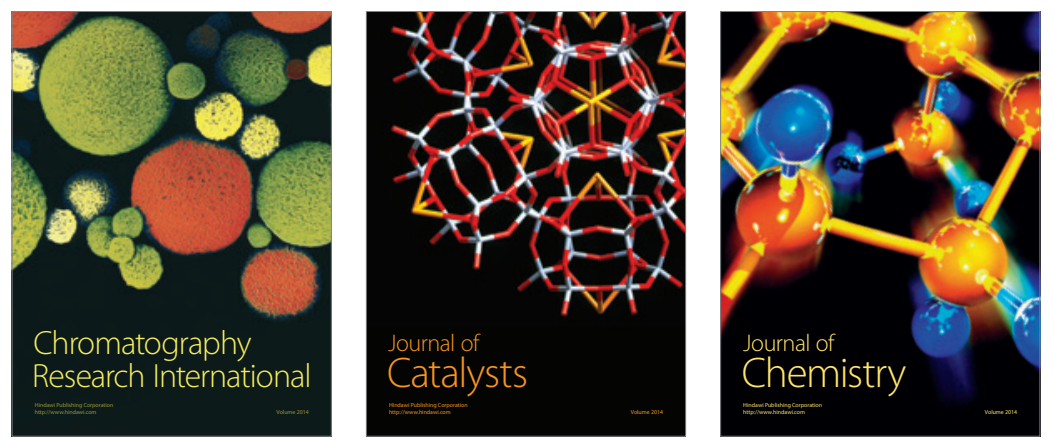
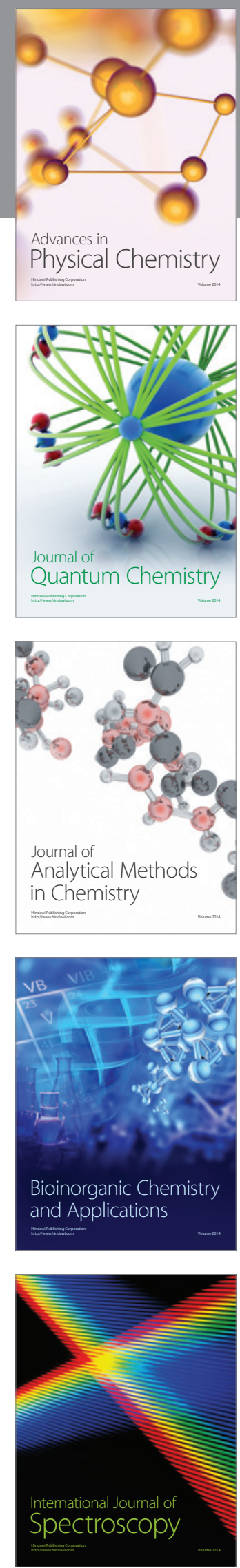